\title{
PEDRO PAULO, EGYPTOMANIA AND ME
}

Margaret Marchiori Bakos ${ }^{1}$

I met Pedro Paulo Funari first through his books, of which "Greece and Rome" introduced me to the study of Classical Antiquity.

When I was nearly forty years old, and I was teaching Classical History for the first time, I was fascinated by the didactic and objective method with which Pedro Paulo Funari introduced this complex era of Humanity's History. Soon, my students started to buy his books and multiply his name in PUCRS and Rio Grande do Sul.

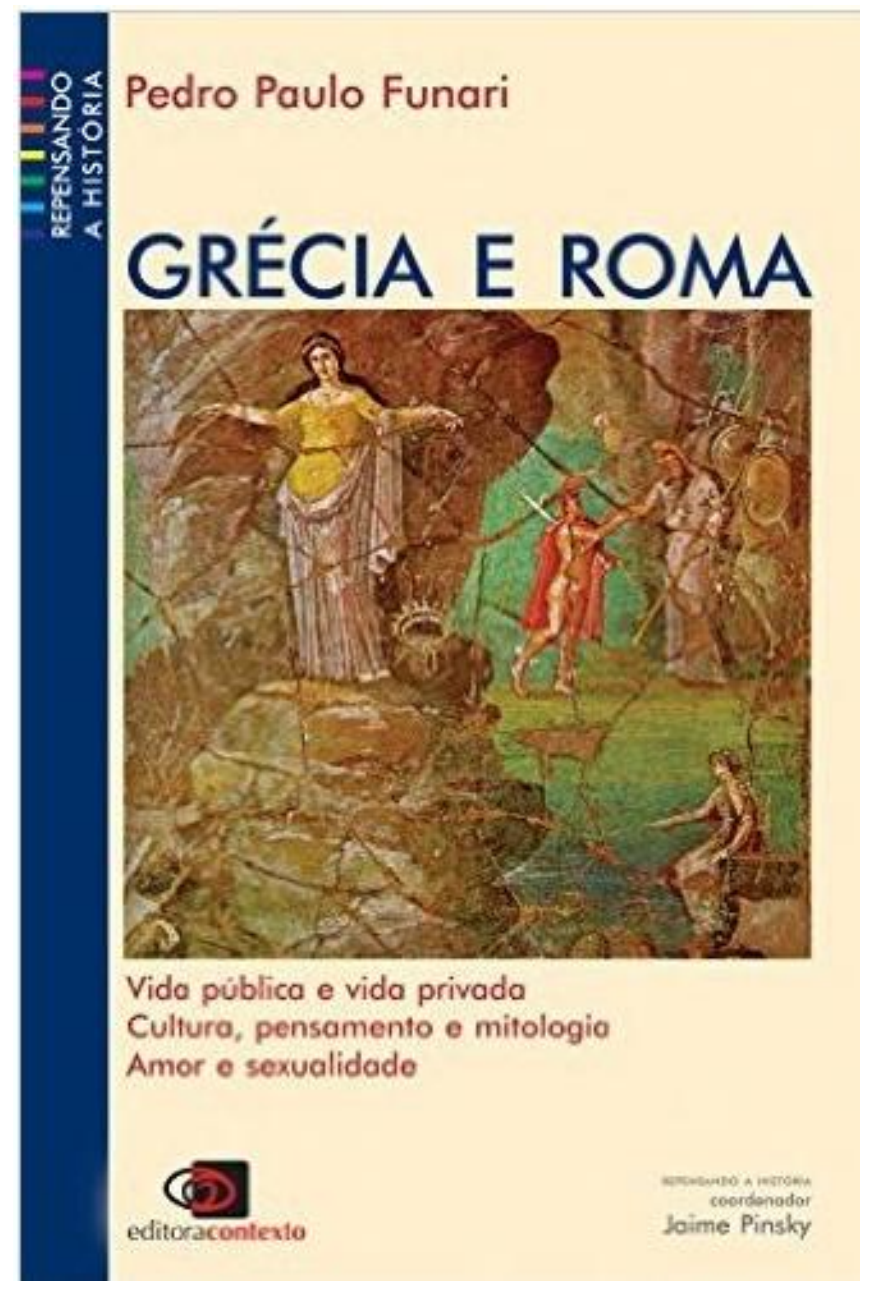

\footnotetext{
1 Assistant Professor, Londrina State University, Londrina, Brazil. E-mail: megbakos@gmail.com
} 
The second contact with the author was on the Internet, following my postdoctoral fellowship in Egyptology at University College London in 1989. One fine day, I received an e-mail from Pedro Paulo at my newly opened PC; it was an invitation to speak in a seminar on Ancient History! I remember, exactly, that my positive answer to his invitation took at most two minutes to be answered by him!

On this occasion, I joined him in a new world, whose access and dominance had long been known by my colleague from São Paulo.

It was in this passage to the cyber world that Pedro Paulo introduced me to a fascinating character: Professor Dr. Peter Ucko, (1938 - 2007), former Director of the Institute of Archeology at University College London. Peter Ucko made an important contribution to the academic world in archeology, notably through his work on the art of rocks in the Paleolithic period.

Peter John Ucko was a refugee son of Central Europe, who arrived in London in 1938. He developed a fascination for Egyptology as a child, which led him to complete his studies in anthropology at University College. He was notable for his innovative work in which he integrated Archeology and Anthropology in the study of Material Culture.

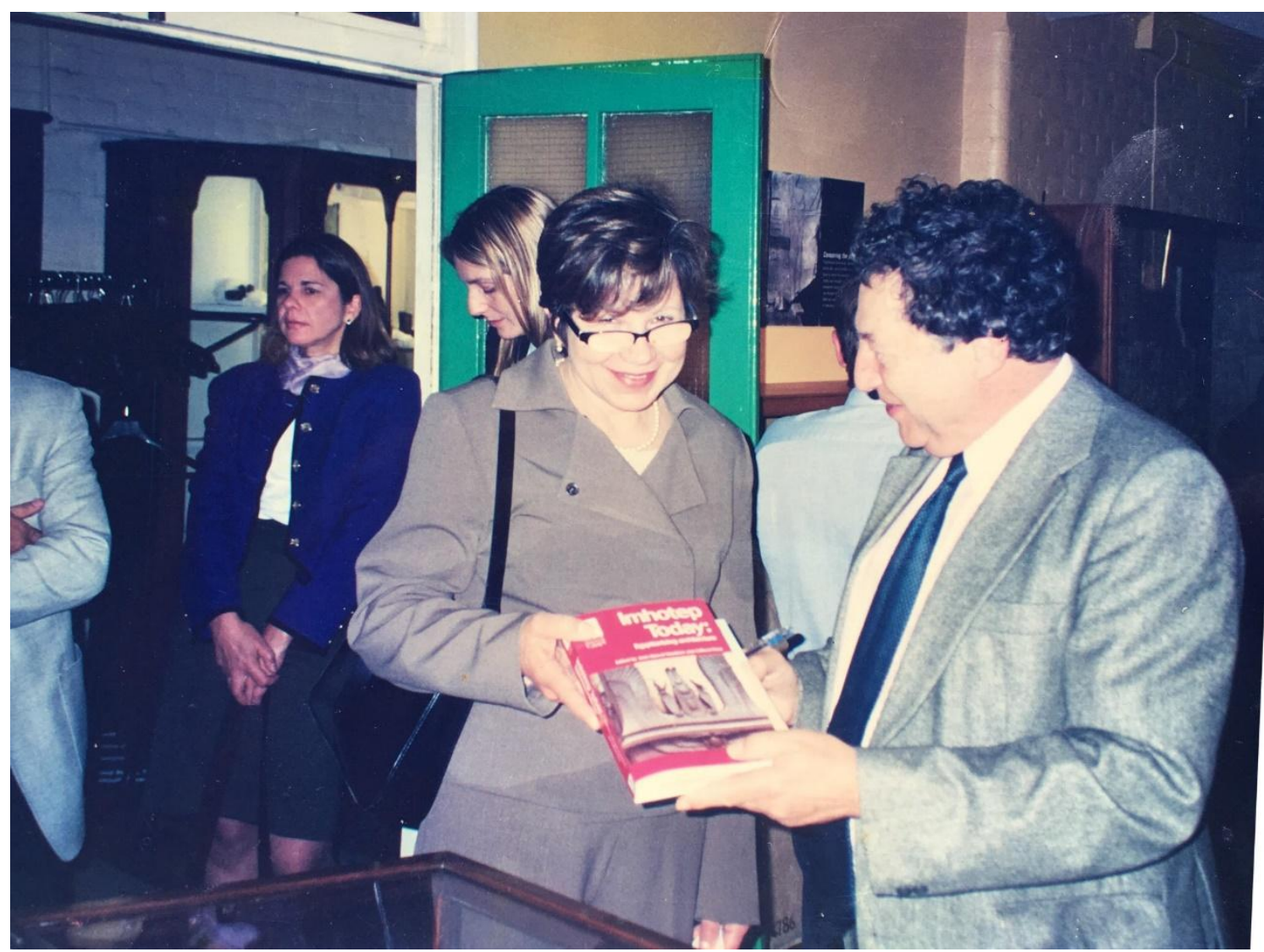


I already knew, and had read, Peter Ucko's book "Man, Settlement, and Urbanism", a basic and indispensable book on the development of urban and non-urban settlements throughout History. When, through Pedro Paulo Funari, I was invited to write a chapter in one of the eight volumes Ucko was editing at the beginning of the Second Millennium, I was extremely honored. The volume containing my chapter was titled "Imhotep Today: egyptianizing archictecture".

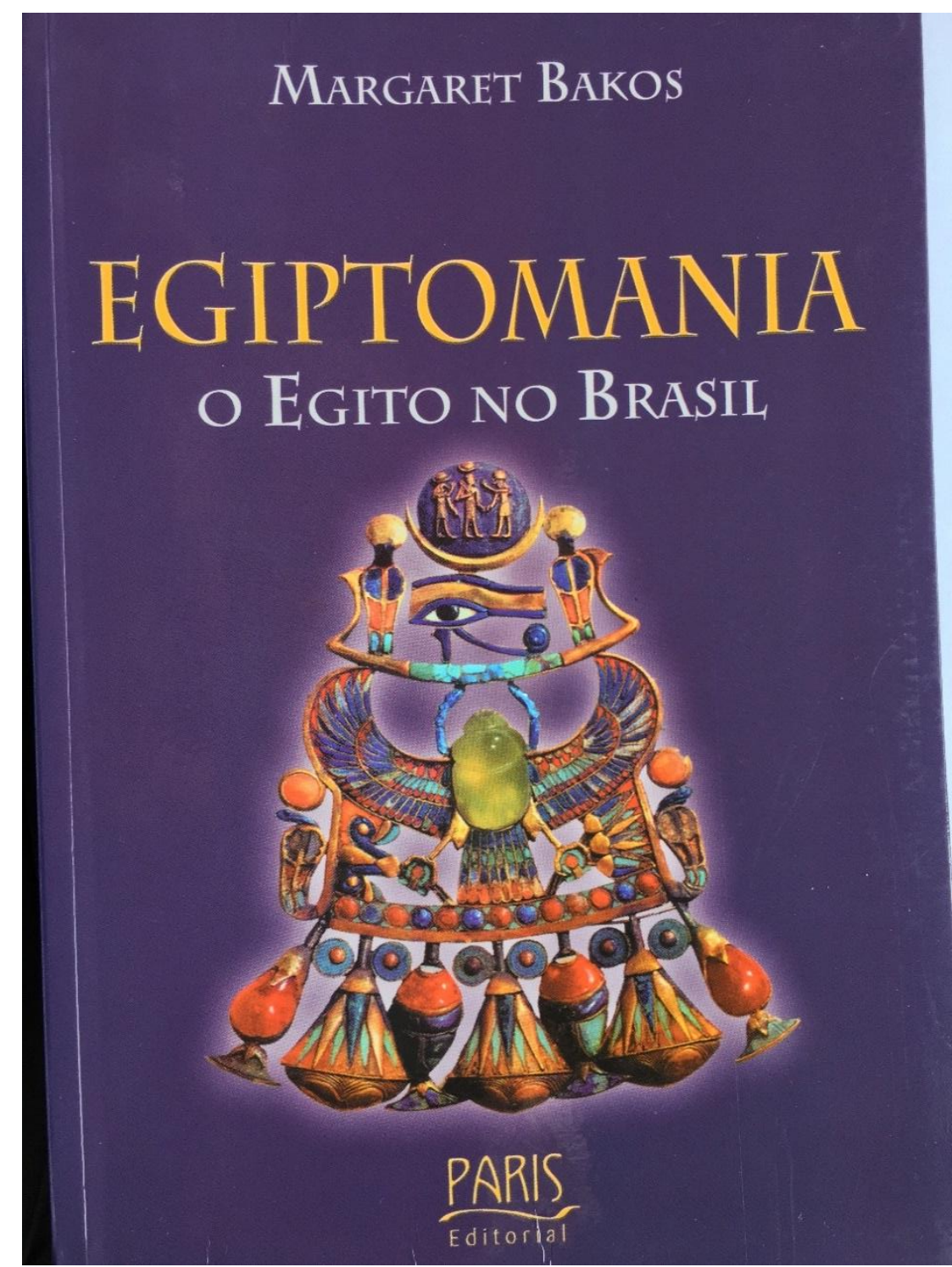

In 2003 I traveled to London for the release of the eight volumes and also to meet personally Peter Ucko!

From this extraordinary contact, my respect for Pedro Paulo and his select circle of academic coexistence grew larger, especially when I met Raquel, his wife, who was very interested in Ancient Egypt, which further strengthened our friendship. In the meantime, the theme of my 
chapter in University College's book - "Egyptianizing Motifs in Architecture and Art in Brazil" - had become popular in Brazil. So we went, my husband and I, Lucio, to São Paulo to be introduced by Pedro Paulo Funari to Editora Contexto, who might be interested in publishing a book on the subject.

In fact, I was already promoting an annual PUCRS event titled "Jornadas de Estudos do Oriente Antigo", which reached twenty consecutive editions. In 2004, the book "Egiptomania. O Egito no Brasil ", was presented in one of those Conferences with the presence of Jean Marcel Humbert, the most prominent scholar and disseminator of "Egyptomania "in the World.

Of course, there were many opportunities for work and coexistence between Pedro Paulo and me, from then on. At the moment, I am part of a research, led by him and his students, entitled "Usos do Passado", where I think Egyptomania is included and, therefore, remains in evidence. We joined the theme since 2003. Pedro Paulo encouraged me in a way that only a colleague, a very close friend, would do.

I pay a very sincere tribute to Pedro Paulo Funari for all his support to me, together with a very warm "thank you very much". 